\title{
School Size and Incidents of Violence among Texas Middle Schools
}

\author{
Elizabeth A. Kohler \\ Department of Educational Leadership and Counseling, Box 2119 \\ Sam Houston State University, Huntsville, Texas 77341-2119, USA \\ Tel: 1-713-582-5361Ｅ-mail: efielder1@kleinisd.net
}

Anthony J. Onwuegbuzie (Corresponding author)

Department of Educational Leadership and Counseling, Box 2119

Sam Houston State University, Huntsville, Texas 77341-2119, USA

Tel: 1-936-294-4509Ｅ-mail: tonyonwuegbuzie@aol.com

\author{
Julie P. Combs
}

Department of Educational Leadership and Counseling, Box 2119

Sam Houston State University, Huntsville, Texas 77341-2119, USA

Tel: 1-936-294-3181_E-mail:.jpc002@shsu.edu

\section{Rebecca M. Bustamante}

Department of Educational Leadership and Counseling, Box 2119

Sam Houston State University, Huntsville, Texas 77341-2119, USA

Tel: 1-936-294-4946_E-mail: rmb007@shsu.edu

\section{Stacey L. Edmonson}

Department of Educational Leadership and Counseling, Box 2119

Sam Houston State University, Huntsville, Texas 77341-2119, USA

Tel: 1-936-294-1101 E-mail: sedmonson@shsu.edu 
Received: May 22, 2015 Accepted: June 28, 2015 Published: June 29, 2015

doi:10.5296/jei.v1i1.7656

URL: http://dx.doi.org/10.5296/jei.v1i1.7656

\begin{abstract}
Although many studies have been conducted regarding (a) school violence in middle schools and (b) the size of schools, to date, no researcher appears to have examined the role that the size of the middle school plays in determining incidents of violence specifically fighting, assaults, and aggravated assaults. Thus, the purpose of this study was to examine the relationship between the incidents of school violence, specifically fighting, assaults, and aggravated assaults, and the size of middle schools in the state of Texas for 3 school years. All 842 middle schools in Texas were included in this study. Compared to small schools, medium schools, and large schools, very small schools had a statistically significantly lower proportion of students involved in assaults, proportion of students involved in aggravated assaults, proportion of incidents of assaults, and proportion of incidents of aggravated assaults. Further, very small schools had a statistically significantly lower proportion of students involved in fights and proportion of incidents of fights than did large schools. A trend emerged across the 4 school sizes for all 6 indicators of school violence, which, in every case, reflected a sharp increase from very small schools to small schools - peaking at small schools. Thus, very small schools appear to be at a greater advantage than are other types of schools with respect to incidents of school violence. Implications of the findings are discussed.
\end{abstract}

Keywords: School size, School violence, Incidents of school violence, Aggressive behavior, Texas middle schools

\title{
1. Introduction
}

With violence and aggressive behavior coming to a peak during the adolescent years (Valois, MacDonald, Bretous, Fischer, \& Drane, 2002), determining how the size of the middle school impacts student engagement in incidents of school violence, specifically fighting, assault, and aggravated assault, will provide beneficial information to educators as they plan to structure current buildings and plan for future construction of middle schools. Although many studies have been conducted regarding (a) school violence in middle schools (e.g., Kerbs \& Jolley, 2007) and (b) the size of schools (e.g., Lay, 2007), to date, no researcher appears to have examined the role that the size of the middle school plays in determining incidents of violence specifically fighting, assaults, and aggravated assaults. Thus, the purpose of this research study was to examine the relationship between the incidents of school violence and the size of middle schools in the state of Texas. Specifically, the following research question was addressed: What is the relationship between incidents of school violence, specifically fighting, assaults, and aggravated assaults, and the size of the middle schools in the state of Texas? It was hoped that the results of this study would provide valuable information to help educators understand better the role that the size of the middle school plays in the formation and frequency of school violence. 


\subsection{Theoretical Framework}

Decades have passed since the formal research into violence and aggression first began back in the early 1900s (Amodei \& Scott, 2002). Generally, psychologists acknowledge that there is not a single factor responsible for the expression of violence (Amodei \& Scott, 2002). Even though there is a societal resignation about the inevitability of youth violence, successful intervention measures can possibly prevent youth from becoming involved in incidents of violence (Amodei \& Scott, 2002). Social learning theory speculates that aggressive behavior is learned rather than inborn (Bandura, 1977). According to the theory, aggressive behavior is gained through observational learning (e.g., seeing aggressive behavior modeled in real life or the media), direct experience (e.g., being rewarded for aggressive behavior), and self-regulation (e.g., rewarding or punishing oneself for manifesting the behavior) (Bandura \& Walters, 1959). With aggressive behavior being one of the major problems in schools, social learning theory offers one explanation for this deviant behavior (Alexander \& Langford, 1992).

Another explanation for deviant behavior is the sociological version of social learning theory developed by Akers and his colleagues (Akers, 1985; Akers, Krohn, Lanza-Kaduce, \& Radosevich, 1979). Akers' social learning theory differs from Bandura's theory in that Akers et al. (1979) theorized that "the principal behavioral effects come from the interaction in or under the influence of those groups which control individuals' major sources of reinforcement and punishment and expose them to behavioral models and normative definitions" (p. 638). In the larger school environments, students begin to feel isolated and alienated because students are more likely to have encounters with strangers in larger schools than with peers and adult staff with whom they are familiar (Leung \& Ferris, 2008). As these feelings of isolation and alienation continue, the students form groups, such as gangs, and allegiances with each other, further removing themselves from other groups of students (Alexander \& Langford, 1992; Leung \& Ferris, 2008). Then, these groups of students begin to develop a set of behaviors, such as fighting or physical violence, where they witness others engaging in deviant behaviors. As a result, this deviant behavior is reinforced through exposure to and recognition of the deviant behavior (Alexander \& Langford, 1992). Bandura (1977), Akers (1973, 1985), and Akers et al. (1979) provide an explanation for deviant behaviors among adolescents. There are numerous factors that contribute to aggressive and violent behaviors such as peer and family influences, as well as exposure to displays of good and bad behaviors. These theoretical frameworks might aid in the understanding of why incidents of school violence differ within small and large schools.

\section{Method}

\subsection{Participants and Instruments}

This study involved the use of convenience sampling (Onwuegbuzie \& Collins, 2007). In the current study, archival discipline data indicating numbers of specific discipline incidents (e.g., referrals to school principals) that were collected by the Texas Education Agency (TEA) and stored in the Public Education Information System (PEIMS) database were examined. The PEIMS database is a system that encompasses all the data collected from public education 
schools and school districts including student demographics, academic performance, student discipline, and organizational information (TEA, 2008). According to TEA (2008), all of the data are collected electronically based on the procedures set forth in the PEIMS Data Standards. The selected population for this study represented middle schools in the state of Texas.

The selected middle schools contained students in the sixth, seventh, and eighth grades. Charter schools and alternative schools or any other school that did not meet the definition of a middle school were not included in this study, yielding a final sample size of 842 middle schools. Further, the target sample consisted of different-sized middle schools (i.e., very small, small, medium, large, and very large). Additionally, the discipline data were requested from TEA for the 2006-2007, 2007-2008, and 2008-2009 school years. The discipline data indicated the size of the school where high and low levels of violent incidents occurred, specifically fighting, assaults, and aggravated assaults.

\subsection{Procedures}

Upon approval from the Institutional Review Board (IRB), a request was submitted to the PEIMS database coordinators in order to retrieve the archival data consisting of the discipline records of middle schools, as previously defined. The purpose for selecting more than 1 school year was to ensure that schools identified as having low or high incidents of violence indicated patterns over a period of time rather than just demonstrating unusual circumstances throughout the most recent school year. After the data were retrieved, analysis of the 842 middle schools took place.

According to Gay, Mills, and Airasian (2006), the researcher can use archival data in a study "to gain valuable historical insights, identify potential trends, and explain how things got to be the way they are" (p. 422). Next, the different-sized middle schools were analyzed to determine the high and low levels of school violence, proportional to the size of the school. From this analysis, the different-sized middle schools with the high and low incidents of violence were examined to determine whether there was a statistically significant relationship between school size and incidents of violence among middle schools in Texas.

\subsection{Data Analysis}

After the data were retrieved, they were analyzed based on the definitions of very small $(<$ 300 total student enrollment), small (300-599 total student enrollment), medium (600-899 total student enrollment), large (900-1,999 total student enrollment), and very large (2,000 or more total student enrollment) middle schools, as defined by the Division of Accountability Research at TEA (1999). The data were analyzed using the Statistical Package for the Social Sciences (SPSS) to determine the size of middle schools that have high and low incidents of violence. After a correlational analysis had been conducted, an analysis of variance (ANOVA) was conducted to compare the number of incidents of school violence among the five size groups (i.e., very small, small, medium, large, very large) of the middle schools. None of the 842 schools met the enrollment criteria for being deemed a very large school, thereby resulting in an ANOVA that compared four size groups. This test also helped to examine 
whether there was a linear trend in incidents of violence as a function of size of school. A 5\% level of statistical analysis was used for the ANOVA.

\section{Results}

The research question was analyzed using SPSS version 17 to determine the size of middle schools that have high and low incidents of violence. For each analysis conducted, the independent variable was the mean size of the school, which represented the mean school size over a 3-year period (i.e., 2006-2009) (cf. Table 1), and the dependent variable was incidents of school violence (i.e., fighting, assaults, and aggravated assaults).

Table 1. Mean and standard deviation for the discipline variables and school size variable ( $n$ $=842$ )

\begin{tabular}{|l|l|l|}
\hline Variable & $M$ & $S D$ \\
\hline Proportion of Students Involved in Fights & 77.76 & 78.85 \\
\hline Proportion of Students Involved in Assaults & 5.14 & 7.75 \\
\hline Proportion of Students Involved in Aggravated Assaults & 0.33 & 8.60 \\
\hline Proportion of Incidents of Fights & 61.14 & 67.76 \\
\hline Proportion of Incidents of Assaults & 4.94 & 7.48 \\
\hline Proportion of Incidents of Aggravated Assaults & 0.32 & 0.85 \\
\hline Mean School Size (2007-2009) & 796.17 & 395.60 \\
\hline
\end{tabular}

\subsection{Correlational Findings}

Because all of the coefficients suggested non-normality, Spearman's correlation coefficient (i.e., Spearman's rho) was performed. Because six correlation coefficients were computed, a Bonferroni adjustment was applied to avoid the total experimentwise error rate exceeding 5\% (Chandler, 1995), which yielded an adjusted level of statistical significance of .0083 (i.e., . $05 / 6=.0083$ ). After applying this adjustment, the series of Spearman's rho correlations revealed that all six discipline variables were statistically significantly related to school size. Cohen's (1988) criteria suggested that these correlations represented either small or medium relationships. The stronger correlations involved the proportion of students who commit assaults and the proportion of incidents of students committing assaults (cf. Table 2). 
Table 2. Spearman's rho correlations between school size and the six discipline variables

\begin{tabular}{|l|l|}
\hline Variable & School Size \\
\hline Students Involved in Fights Proportional & $.12^{*}$ \\
\hline Students Involved in Assaults Proportional & $.26^{*}$ \\
\hline Students Involved in Aggravated Assaults Proportional & $.17^{*}$ \\
\hline Number of Incidents of Fights Proportional & $.12^{*}$ \\
\hline Number of Incidents of Assaults Proportional & $.25^{*}$ \\
\hline Number of Incidents of Aggravated Assaults Proportional & $.17^{*}$ \\
\hline
\end{tabular}

Note. ${ }^{*} p<.001$.

\subsection{ANOVA Findings}

Further, a nonparametric ANOVA was conducted. Specifically, a series $(n=6)$ of Kruskal-Wallis tests was employed, one test for each dependent variable. The Kruskal-Wallis tests revealed a statistically significant difference among the four middle school size categories with respect to all six dependent variables (cf. Table 3). Using Cohen's (1988) criteria, school size had a small-to-moderate relationship with the proportion of students involved in assaults and the proportion of incidents of aggravated assault occurring on middle school campuses. School size had a small relationship with the other variables.

Table 3. Findings pertaining to the Kruskal-Wallis test

\begin{tabular}{|l|l|l|l|l|}
\hline Variable & $\mathrm{X}^{2}$ & $\mathrm{df}$ & $p$-value & $\begin{array}{l}\text { Effect Size } \\
\text { (Cramer's } V \text { ) }\end{array}$ \\
\hline Proportion of Students Involved in Fights & 12.84 & 3 & .005 & .07 \\
\hline Proportion of Students Involved in Assaults & 124.17 & 3 & $<.0001$ & .22 \\
\hline Proportion of Students Involved in Aggravated Assaults & 25.58 & 3 & $<.0001$ & .10 \\
\hline Proportion of Incidents of Fights & 14.93 & 3 & $<.0001$ & .08 \\
\hline Proportion of Incidents of Assaults & 25.56 & 3 & $<.0001$ & .10 \\
\hline Proportion of Incidents of Aggravated Assaults & 123.17 & 3 & $<.0001$ & .22 \\
\hline
\end{tabular}

Note. $\mathrm{df}=$ degrees of freedom. 


\subsection{Trend Analysis}

A series $(n=6)$ of tests of orthogonal polynomials was conducted to examine the trend of the incidents of school violence, specifically, the trend in fighting, assaults, and aggravated assaults across the four school size types. With respect to the proportion of students involved in fights, a test of orthogonal polynomials revealed a quadratic trend, $F(1,838)=8.68, p$ $=.003$. Specifically, the proportion of students involved in fights increased sharply from very small schools to small schools-peaking at small schools, before decreasing slightly and linearly for medium schools and large schools. In contrast, with regard to the proportion of students involved in assaults, a cubic trend emerged, $F(1,838)=8.68, p=.003$. Specifically, the proportion of students involved in assaults increased sharply from very small schools to small schools - peaking at small schools, before decreasing somewhat sharply for medium schools and less sharply between middle schools and large schools. With respect to the proportion of students involved in aggravated assaults, a linear trend was revealed, $F(1,838)$ $=5.05, p=.025$. Specifically, the proportion of students involved in aggravated assaults increased sharply from very small schools to small schools - peaking at small schools, before decreasing very slightly for both medium and large schools. With regard to the proportion of incidents of fights, a quadratic trend emerged, $F(1,838)=14.80, p<.0001$. Specifically, the proportion of incidents of fights increased very sharply from very small schools to small schools - peaking at small schools, before decreasing sharply and approximately linearly for medium schools and large schools. With respect to the proportion of incidents of assaults, a quadratic trend also was revealed, $F(1,838)=3.86, p=.05$. Specifically, the proportion of incidents of assaults increased very sharply from very small schools to small schools - peaking at small schools, before decreasing sharply and approximately linearly for medium schools and large schools. Finally, with regard to the proportion of incidents of aggravated assaults, a cubic trend emerged, $F(1,838)=5.40, p=.02$. Specifically, the proportion of incidents of aggravated assaults increased very sharply from very small schools to small schools - peaking at small schools, before decreasing somewhat sharply for medium schools and less sharply between middle schools and large schools.

\section{Discussion}

The series of Spearman's rho correlation coefficients revealed that all six discipline variables were statistically significantly related to school size. Interestingly, the strongest relationships between discipline and school size were those that involved the proportion of students who commit assaults and the proportion of incidents of students committing assaults. Therefore, as school size increases, to a small to moderate degree, the proportion of students involved in violent incidents and the proportion of incidents also increase. Numerous studies have indicated that levels of violence are more common in larger schools than in smaller schools (i.e., Ferris \& West, 2004). More specifically, Ferris and West (2004) compiled data from National Center for Education Statistics (NCES) information that was distributed in 2001. These data indicated that "school violence rapidly rises with school size and almost exponentially so for seriously violent crimes" (p. 1681). On the other hand, these results also somewhat support the findings of a study conducted by Chen and Weikert (2008), which revealed that "the effect of school size is small and often insignificant in affecting school 
safety and student performance" (p. 15). The findings from both of these studies lead to the conclusion that school violence increases with school size, but the results vary as to the degree to which there is an effect. The results of the present study provide incremental validity to this conclusion because the effect of school size ranged from small to moderate.

The Kruskal-Wallis tests revealed a statistically significant difference among the four middle school size categories with respect to all six dependent variables. Using Cohen's (1988) criteria, the school size had a small to moderate effect on the proportion of students involved in assaults and the proportion of incidents of aggravated assaults occurring on middle school campuses in the state of Texas. School size had a small effect on the other variables.

Compared to small schools, medium schools, and large schools, very small schools had a statistically significantly lower proportion of students involved in assaults, proportion of students involved in aggravated assaults, proportion of incidents of assaults, and proportion of incidents of aggravated assaults. Further, very small schools had a statistically significantly lower proportion of students involved in fights and proportion of incidents of fights than did large schools. Thus, very small schools appear to be at a greater advantage than are the other types of schools with respect to incidents of school violence. According to Dinkes, Cataldi, and Lin-Kelly (2007), the percentage of schools reporting serious crimes was three times higher for large schools (1,000 or more students) than for middle-sized schools (300 to 999) in both city and urban schools.

The tests of orthogonal polynomials revealed either a linear, quadratic, or cubic trend for each of the six indicators of violence. These findings support what many other researchers have documented: smaller schools experience proportionally less violence and behavior problems from students than do larger schools (e.g., Ferris \& West, 2004).

According to Akers et al. (1979), behaviors develop through imitation (i.e., duplication of a behavior after viewing another individual demonstrating that same behavior) or modeling. Individuals imitate each other because they have been vicariously reinforced to engage in a behavior, because they have seen another individual engage in this behavior and be rewarded, or because of operant conditioning (i.e., behavior is directly rewarded). The significant relationship between school size and incidents of violence documented in this study lends support to this theory. As school size increases, so does the level of violent incidents. Larger schools likely will have more opportunities for students to witness violent incidents; thus, more students are likely to duplicate this behavior.

\subsection{Recommendations for Policy}

According to Welsh, Stokes, and Greene (2000), disciplinary records partially reflect the implemented policies within each individual school district, resulting in some variation in the actual numbers of disciplinary incidents. Within each school district, a policy should be established to refer to the TEA definitions of fighting, assaults, and aggravated assaults in an effort to avoid any under- or over-reporting of these incidents.

Taylor, Liang, Tracy, Williams, and Seigle (2002) recommended starting with a prevention program in the elementary schools to help students adjust to transitioning to middle school by 
providing the students with problem solving and social skills. Policymakers should take a more proactive approach in preparing youth for the challenges ahead by implementing policies to educate students on how to resolve conflict and to deal with the many facets of peer pressure in their school environments. However, policies are usually implemented as a reactive approach to school violence.

With the development of large schools on the rise (Hampel, 2002), many educators and policy-makers have argued that large schools cannot provide for the human aspect of schooling as can smaller schools (Lay, 2007) because they create an environment of impersonality and anonymity (Chen \& Weikart, 2008). In response to the levels of incidents of violence, political leaders, school administrators, and law enforcement officials have turned their focus to finding solutions and preventative measures to curb some of the violence occurring on school campuses (Solomon, Bradshaw, Wright, \& Cheng, 2008). Consideration should be given in the creation of curriculum to support the human aspect of schooling in the larger schools due to the fact that it is a permanent feature.

\subsection{Recommendations for Practice}

National statistics continue to indicate that physical fighting is the most common form of school violence among students (Meyer, Astor, \& Behre, 2004). According to Dinkes et al. (2007), the largest percentage of schools reported that the disciplinary actions taken for the 2005-2006 school year were in response to a physical attack or a fight, with $32 \%$ of schools indicating that the disciplinary action was serious. Conducting a needs assessment should be the first step in identifying the strengths and risks of the schools so that a prevention program could be created based on the needs of that school (Furlong, Felix, Sharkey, \& Larson, 2005). Identifying those students who have a history of violent behavior, show signs of anger, or are engaged in aggressive behaviors would be beneficial because anger is the single most significant predictor of aggressive behavior (Fong, B. L. Vogel, \& R. E. Vogel, 2008). In addition, identifying those students who are economically disadvantaged is important so that appropriate interventions can be put in place. These students need support not only within school but also outside of school with family supports. The number of economically disadvantaged students at each campus will vary depending on the size and location of the school. Teachers, counselors, and administrators should take a more proactive approach in responding to the needs of the students on their campuses. This proactive approach could include intervention and prevention programs to help students manage better their levels of anger in an effort to minimize incidents of violence on campuses.

\subsection{Recommendations for Future Research}

Future research should explore very small schools in more detail because this was the size of middle school that had a statistically significantly lower proportion of students involved in violent incidents and a statistically significant lower proportion of violent incidents. Additionally, an examination of large-sized middle schools with low levels of violence should be examined. Because so many large-sized middle schools currently exist throughout the United States, understanding the systems and structures that best support students could provide school leaders of large-sized middle schools with information to make decisions that 
best support the students. Further, schools with high levels of economically disadvantaged students but low levels of violence should be studied. An examination of these campuses might reveal programs, interventions, systems, and/or structures that are effective in addressing the needs of those students who have unique family situations and economic status. This information would be beneficial to school leaders so that at-risk students can be appropriately supported at school.

A more detailed examination of why middle school students fight should be explored because compared to all other age groups, adolescents have more frequently engaged in fighting (Franke, Huynh-Hohnbaum, \& Chung, 2002). Fighting has been the most common form of dysfunctional behavior that adolescents have exhibited as they learn to deal with the many changes that they are experiencing (Wright \& Fitzpatrick, 2006). Additionally, future research should explore the relationship between fighting and academic success. Students who participate in fights have been found to be less likely to be successful in their studies (Valois et al., 2002).

\section{Conclusions}

Physically aggressive behavior continues to be a major concern in the school environment (Alexander \& Langford, 1992). This kind of physically aggressive behavior interferes with the learning environment at all school levels (Alexander \& Langford, 1992). When students are not engaged in their academic studies at school, they are more likely to become aggressive (Graham, Bellmore, \& Mize, 2006), especially during the adolescent years when violence and aggression hits a climax (Valois et al., 2002). Creating a safe, supportive school is essential to the academic and overall social well-being of the students (Furlong et al., 2005).

Overwhelming evidence exists to support the claim that incidents of school violence are much less likely to occur in small schools than in large schools (Amodei \& Scott, 2002; Ferris \& West, 2004; Leung \& Ferris, 2008). With violence and aggressive behavior coming to a peak during the adolescent years (Valois et al., 2002), determining how the size of the middle school impacts student engagement in incidents of school violence, specifically fighting, assault, and aggravated assault, provides beneficial information to educators as they plan to structure current buildings and plan for future construction of middle schools. For the current larger-sized middle schools, the current findings suggest that administrators should consider creating smaller environments within the schools (e.g. teaming, communities, separation of grade levels) so that students are known among their teachers to provide an environment where students feel welcome, decreasing the feeling of isolation.

The results of this study reveal a small to moderate effect on incidents of violence as a function of school size. However, as the results indicate, school size is not necessarily the only factor that plays a role in the level of violence. Every school district and every campus utilizes a variety of supports and structures, such as teaming, scheduling, organization of the grade levels, and prevention programs. These supports and structures play a role in addressing the needs of the students and the morale of the staff and students. If the appropriate systems are in place, the discipline management in the classroom becomes 
second as the learning and academic achievement of the students comes first. School leaders are ultimately responsible for ensuring that learning is taking place in the classroom-an accomplishment not attainable with constant classroom disruptions. Thus, it is important not only to understand the size of middle schools where less violence is likely to occur, but also to understand why there is less violence occurring on different-sized campuses, so that students are able to focus more on their academic studies.

\section{References}

Akers, R. L. (1973). Deviant behavior: A social learning approach. Belmont, CA: Wadsworth.

Akers, R. L. (1985). Deviant behavior: A social learning approach (3rd ed.). Belmont, CA: Wadsworth.

Akers, R. L., Krohn, M. D., Lanza-Kaduce, L., \& Radosevich, M. (1979). Social learning and deviant behavior: A specific test of a general theory. American Sociological Review, 44, 636-655. http://dx.doi.org/10.2307/2094592

Alexander Jr., R., \& Langford, L. (1992). Throwing down: A social learning test of students fighting. Social Work in Education, 14, 114-124.

Amodei, N., \& Scott, A. A. (2002). Psychologists' contribution to the prevention of youth violence. The Social Science Journal, 39, 511-526. http://dx.doi.org/10.1016/S0362-3319(02)00226-4

Bandura, A. (1977). Social learning theory. Englewood Cliffs, NJ: Prentice Hall.

Bandura, A., \& Walters, R. H. (1959). Adolescent aggression. New York, NY: Ronald.

Chandler, C. R. (1995). Practical considerations in the use of the simultaneous inference for multiple tests. Animal Behaviour, 49, 524-527. http://dx.doi.org/10.1006/anbe.1995.0069

Chen, G., \& Weikert, L. A. (2008). Student background, school climate, school disorder, and student achievement: An empirical study of New York City's middle schools. Journal of School Violence, 7(4), 3-20. http://dx.doi.org/10.1080/15388220801973813

Cohen, J. (1988). Statistical power analysis for the behavioral sciences (2nd ed.). Hillsdale, NJ: Lawrence Erlbaum.

Dinkes, R., Cataldi, E. F., \& Lin-Kelly, W. (2007). Indicators of School Crime and Safety: 2007 (NCES 2008-021/NCJ 219553). National Center for Education Statistics, Institute of Education Sciences, U.S. Department of Education, and Bureau of Justice Statistics, Office of Justice Programs, U.S. Department of Justice. Washington, DC.

Ferris, J. S., \& West, E. G. (2004). Economies of scale, school violence and the optimal size of schools. Applied Economics, 36, 1677-1684. http://dx.doi.org/10.1080/0003684042000266 856

Fong, R. S., Vogel, B. L., \& Vogel, R. E. (2008). The correlates of school violence: An examination of factors linked to assaultive behavior in a rural middle school with a large 
migrant population. Journal of School Violence, 7, 24-47. http://dx.doi.org/10.1080/15388220 801955521

Franke, T. M., Huynh-Hohnbaum, A. T., \& Chung, Y. (2002). Adolescent violence: With whom they fight and where. Journal of Ethnic and Cultural Diversity in Social Work, 11, 133-158. http://dx.doi.org/10.1300/J051v11n03_01

Furlong, M. J., Felix, E. D., Sharkey, J. D., \& Larson, J. (2005). Preventing school violence: A plan for safe and engaging schools. Principal Leadership, 6(1), 11-15.

Gay, L. R., Mills, G. E., \& Airasian, P. (2006). Educational research: Competencies for analysis and applications (8th ed.). Upper Saddle River, NJ: Pearson.

Graham, S., Bellmore, A. D., \& Mize, J. (2006). Peer victimization, aggression, and their co-occurrence in middle school: Pathways to adjustment problems. Journal of Abnormal School Psychology, 34, 363-378. http://dx.doi.org/10.1007/s10802-006-9030-2

Hampel, R. L. (2002). Historical perspectives on small schools. Phi Delta Kappan, 83, 357-363. http://dx.doi.org/10.1177/003172170208300508

Haselwerdt, M. V., \& Lenhardt, A. M. (2003). Reframing school violence: Listening to voices of students. The Educational Forum, 67, 326-336. http://dx.doi.org/10.1080/00131720308984 581

Kerbs J. J., \& Jolley, J. M. (2007). The joy of violence: What about violence is fun in middle school? American Journal of Criminal Justice, 32, 12-29. http://dx.doi.org/10.1007/s12103-0 07-9011-1

Lay, J. C. (2007). Smaller isn't always better: School size and school participation among $\begin{array}{lllll}\text { young } & \text { people. Social } & \text { Science } & \text { Quarterly, } & 88,\end{array}$ http://dx.doi.org/10.1111/j.1540-6237.2007.00483.x

Leung, A., \& Ferris, J. S. (2008). School size and youth violence. Journal of Economic Behaviour \& Organization, 65, 318-333. http://dx.doi.org/10.1016/j.jebo.2005.10.001

Meyer, H. A., Astor, R. A., \& Behre, W. J. (2004). Teachers' reasoning about school fights, contexts, and gender: An expanded cognitive development domain approach. Aggression and Violent Behavior, 9, 45-74. http://dx.doi.org/10.1016/S1359-1789(02)00115-5

Onwuegbuzie, A. J., \& Collins, K. M. T. (2007). A typology of mixed methods sampling designs in social science research. The Qualitative Report, 12, 281-316. Retrieved from http://www.nova.edu/ssss/QR/QR12-2/onwuegbuzie2.pdf

Solomon, B. S., Bradshaw, C. P., Wright, J., \& Cheng, T. L. (2008). Youth and parental attitudes toward fighting. Journal of Interpersonal Violence, 23, 544-560. http://dx.doi.org/10.1177/0886260507312947

Taylor, C. A., Liang, B., Tracy, A. J., Williams, L. M., \& Seigle, P. (2002). Gender differences in middle school adjustment, physical fighting, and social skills: Evaluation of a social competency program. The Journal of Primary Prevention, 23, 259-272. 
http://dx.doi.org/10.1023/A:1019976617776

Texas Education Agency. (1999). School size and class size in Texas public schools. Policy Research Report No. 12. Austin, TX: Author.

Texas Education Agency. (2008). PEIMS data standards. Retrieved from http://www.tea.state.tx.us/peims/standards/index.html

Valois, R. F., MacDonald, J. M., Bretous, L., Fischer, M. A., \& Drane, J. W. (2002). Risk factors and behaviors associated with adolescent violence and aggression. American Journal of Health Behavior, 26, 454-464. http://dx.doi.org/10.5993/AJHB.26.6.6

Welsh, W. N., Stokes, R., \& Greene, J. R. (2000). A macro-level model of school disorder. Journal of Research in Crime and Delinquency, 37, 243-283. http://dx.doi.org/10.1177/0022427800037003001

Wright, D. R., \& Fitzpatrick, K. M. (2006). Violence and minority youth: The effects of risk and asset factors on fighting among African American children and adolescents. Adolescence, $41,251-262$.

\section{Copyright Disclaimer}

Copyright for this article is retained by the author(s), with first publication rights granted to the journal.

This is an open-access article distributed under the terms and conditions of the Creative Commons Attribution license (http://creativecommons.org/licenses/by/3.0/). 